\title{
Algunas consideraciones sobre la industria ósea del Neolítico y Calcolítico en la Cuenca de Vera, Almería
}

\section{Some considerations about Neolithic and Chalcolithic bone artefacts from Vera Basin, Almería}

\author{
Ruth Maicas Ramos*
}

\begin{abstract}
RESUMEN ABSTRACT
A partir del estudio del material óseo de la Colección Siret, nos acercamos a la funcionalidad de dicho conjunto y a la valoración de este sector artesanal por parte de las sociedades neolíticas y

Bone industry of Siret's collection has been studied in order to know bone artefacts functionality and the social value of this assemblage in Neolithic and chalcolithic societies.
\end{abstract} calcolíticas.

\section{PALABRAS CLAVE}

Industria ósea, Neolítico, Calcolítico, funcionalidad.

\section{KEY WORDS}

Bone Industry, Neolithic, Chalcolithic, functionality.

Presentamos aquí un trabajo realizado, en su mayor parte, a través de los materiales de la colección Siret del Museo Arqueológico Nacional. Nos hemos centrado en los materiales óseos, dentro de una revisión global de los conjuntos conservados, con la intención de aproximarnos a la importancia relativa que la industria ósea tuvo en estos yacimientos.

* Museo Arqueológico Nacional, Serrano, 13, 28001 Madrid. Tfno. 915777912, ext. 249. ruth. maicas@mcu.es 
El estudio se centra en la Cuenca de Vera, unidad biogeográfica que engloba el curso completo del río Almanzora y los ríos menores Aguas y Antas. En este marco se han revisado un total de 270 yacimientos asignados al Neolítico y Calcolítico. En ellos se han podido pormenorizar 145 contextos con un total de materiales que supera las 47000 piezas. De este amplio conjunto, 5389 son objetos realizados sobre materias óseas.

Entendemos por industria ósea aquella que engloba todos los objetos realizados sobre materia dura de origen animal. Quedan exentas pues de este concepto, las piezas con huellas de manipulación no tendentes a la fabricación de objetos (marcas de descarne, etc.), pero no los ecofactos, ya que algunos restos bióticos pueden presentar características similares a las de los objetos de transformación humana y por ello son susceptibles de cubrir unos mismos fines.

La base documental se apoya en el Archivo Siret, cuya consulta ha facilitado la correcta asignación de los materiales, así como las aportaciones concretas al tema que realizó Luis Siret como dibujante, restaurador, analista y arqueólogo experimental.

Hasta la fecha, la información conocida de los materiales óseos de esta colección puede considerarse muy pobre, ya que se centraba en piezas excepcionales, dando una imagen general de escasez (Leisner y Leisner, 1943; Acosta y Cruz-Auñón, 1981: 275-360; Martín de la Cruz, et alii, 2000).

Mediante el estudio de esta colección pretendemos dar a conocer una faceta de la cultura material generalmente olvidada y aproximarnos a la utilización que estos objetos tuvieron en su momento de uso, algo que desde la perspectiva de un museo, es sin duda interesante.

La elaboración de una tipología funcional parte de la aplicación de un test de funcionalidad que como protocolo de actuación, pretende atender a los diversos aspectos que pueden proporcionar información sobre la aplicación que se dio a un objeto de materia ósea. En este sentido, pensamos que la búsqueda de paralelos en sociedades mejor conocidas que las prehistóricas, puede indicar «puntos hacia los que mirar». La morfología general del objeto proporciona también una de las primeras aproximaciones, ya que una determinada forma puede propiciar un uso o imposibilitarlo. En tercer lugar, las proporciones métricas y elección del soporte anatómico, son variables que también descartan directamente algunos usos. La posibilidad de determinar el contexto de aparición y la ergología asociada a este, rechazará así mismo algunas posibilidades abriendo otras. Por su parte el microanálisis, atendiendo a la traceología y a la reconstrucción cinemática, será uno de los factores fundamentales para deducir aspectos funcionales. Junto a los puntos enumerados, contar con análisis físico-químicos permite obtener una documentación precisa no sólo de substancias conservadas, sino también conocer las temperaturas a que fueron sometidos, así como la tenacidad de los materiales. Finalmente los procesos experimentales nos proporcionan un mayor acercamiento al 
objeto de estudio, permitiendo conocer la forma en que se resolvieron en el pasado los problemas que van surgiendo durante la elaboración del objeto. Este protocolo de actuación debería cerrarse con un cálculo de la fiabilidad del sistema, en función de los apartados que han podido cumplimentarse en dicho proceso.

Con estos presupuestos y partiendo de una tipología analítica organizada en 10 categorías (Antropomorfos Apuntados, Denticulados, Biselados, Contenedores, Perforados, Redondeados, Múltiples, Matrices e Indeterminados) nos aproximaremos brevemente a una tipología funcional.

\section{APUNTADOS}

Como ocurre en la mayor parte de las industrias óseas, los apuntados y perforados constituyen los grupos mayoritarios. Siguiendo un criterio de progresivo alejamiento del soporte utilizado por un aumento del grado de elaboración, dividimos los siguientes subgrupos:

\subsection{Punzones de economía y perforadores}

Entre los apuntados que presentan un índice más bajo de transformación, hemos diferenciado los punzones de economía de los que hemos denominado como perforadores, porque aunque ambos presenten características similares, los segundos cuentan con una punta más precisa.

Ambos tienen una alta variabilidad de soportes y parecen corresponder a necesidades puntuales. La función más generalizada, en especial de los segundos, es la realización de orificios de escasa penetración, pero bien definidos.

\subsection{Apuntados anatómicos}

Este segundo subgrupo se caracteriza por un mayor grado de elaboración. Se engloban en esta categoría aquellos apuntados para los que la elección del soporte es un aspecto importante, pero en los que apenas se produce transformación intencional para su utilización como tales útiles.

Destaca entre los tipos documentados, la presencia de apuntados sobre fíbula de suido y ulna de ovicáprido. Pese a su aparente uniformidad morfológica, en ellos se observan rasgos que definen diversas funciones, permitiendo constatar a través de áreas funcionales muy diferentes, las acciones de pinchar, perforar y hender.

Tenemos así, útiles para realizar perforaciones (para lo que se requiere ejercer presión y una punta resistente), útiles para agrandar perforaciones («puntas 


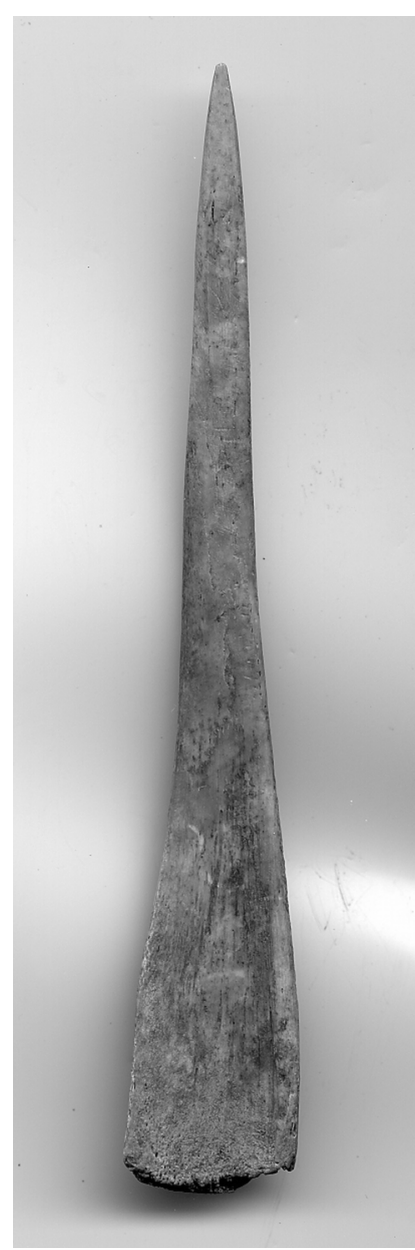

Lam. I. Apuntado sobre fíbula (Almizaraque 40).

largas» en torno a los $5 \mathrm{~cm}$ de longitud de huella de penetración), útiles para pinchar (perforaciones rápidas de escasa penetración sobre elementos que presenten poca resistencia), útiles para decoración cerámica (microfacetas laterodistales, puntas anchas y desviadas y deformaciones de sujeción), uso como paleta (desgastes lateroproximales) que dará lugar a útiles dobles (perforador + espátula), e incluso reutilizaciones de apuntados que pasan a convertirse en pequeños cinceles.

Además de los útiles sobre soportes que podrían considerarse habituales, destaca la presencia de carnívoros, algo que podría responder a una necesidad puntual, pero también a una mayor valoración de objetos realizados sobre una especie cazada. En este sentido, hemos observado su presencia en sepulturas. 


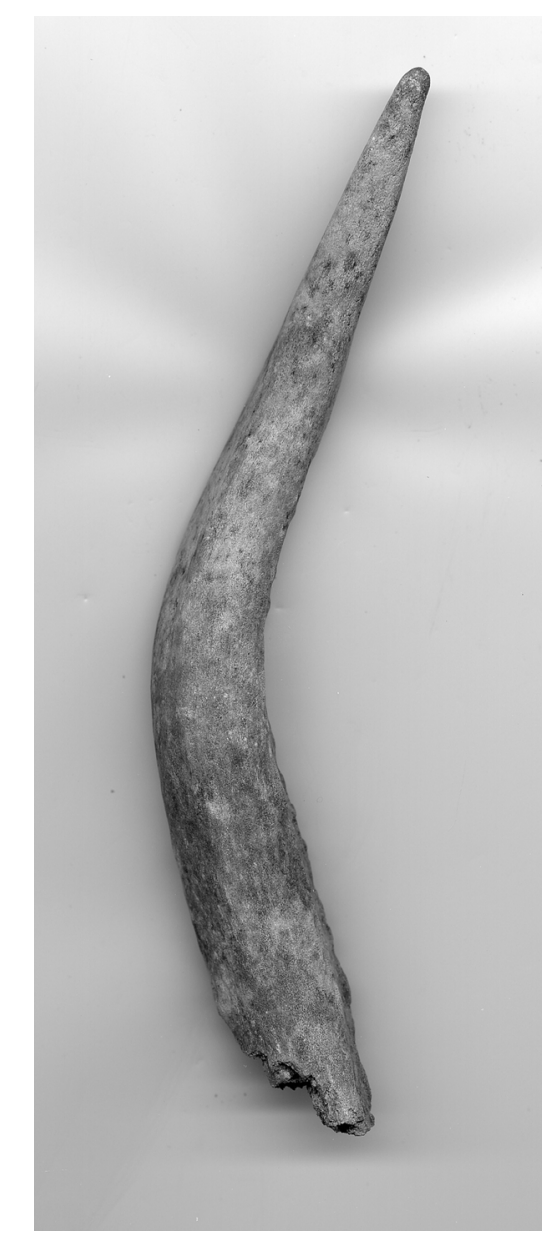

Lam. II. Apuntado sobre asta (Almizaraque 19).

También entrarían en esta categoría los apuntados sobre asta, piezas de baja transformación con formas apuntadas, pero con un bajo índice de penetración y en algunos casos perfil acodado. Proceden en los nueve casos estudiados de contextos de habitación y aunque las huellas observadas no permitan ser concluyentes al respecto, la morfología y parámetros métricos de estas piezas las aproximan a los palos cavadores de madera, utilizados en las labores agrícolas o para marisqueo en terrenos arenosos.

\subsection{Apuntados tubulares}

En el estudio de este subgrupo consideramos muy importante, además de la atención al área funcional, el registro del grado de apertura que configura la punta 


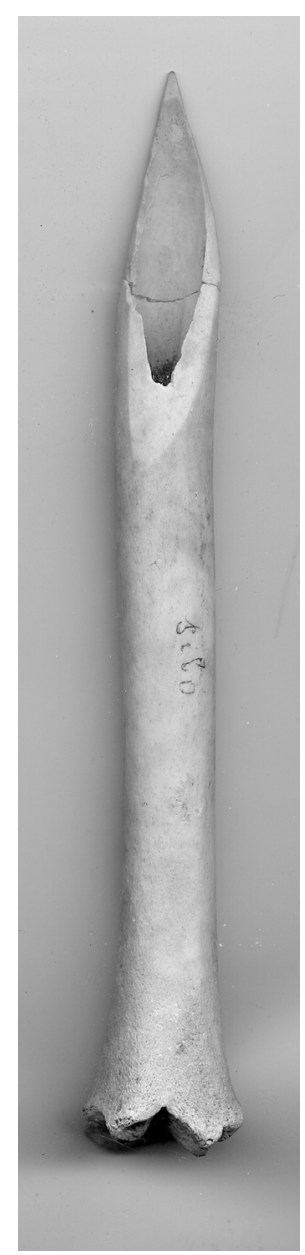

Lam. III. Apuntado tubular (Almizaraque 18).

sobre el canal medular. Definiendo útiles de conducto abierto / cerrado. Cuando el canal presenta una apertura mesial o carece de perforaciones proximales nos encontramos con un elemento punzante "clásico", bien sobre los soportes más frecuentes de tibia y metapodio distal, cuyo éxito generalizado en las distintas industrias postpaleolíticas se debe a la dureza y resistencia de dichos soportes.

Pero además, nos encontramos un conjunto de piezas en las que la apertura del canal desempeña un papel significativo. En este sentido, consideramos que en algunos objetos, se debe primar el papel desempeñado por el canal como conducto viable. La utilidad conjunta de un apuntado resistente y un canal asociado, es difícil precisar en estos momentos, pero las características de los restos documentados en el interior del canal, podrían relacionar estos objetos con los sangradores utilizados por culturas ganaderas. 


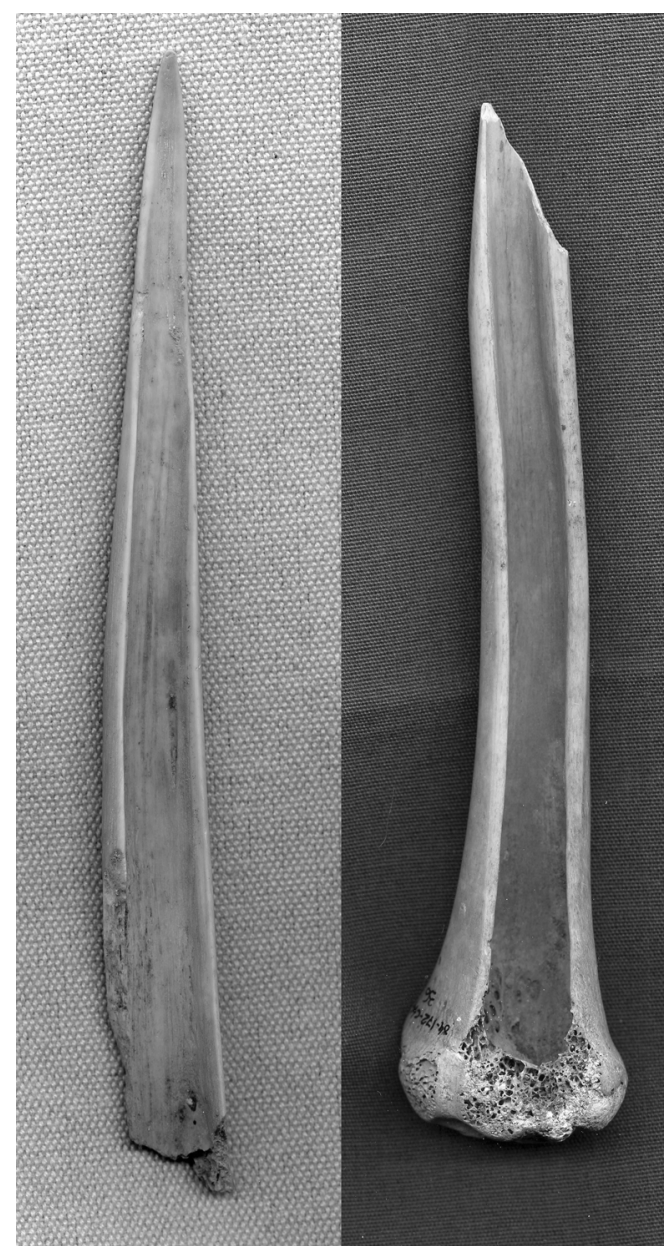

Lam. IV. Puntas de canal de Cuartillas y Almizaraque (Casa 44).

\subsection{Apuntados hendidos}

Otro gran conjunto es el definido por los hendidos, ya más alejados de la morfología natural al corresponder a piezas divididas longitudinalmente. Dentro de este subgrupo, unos presentan menor transformación, como es el caso de los que conservan la base articular, mientras que los de talón trabajado se acercan al subgrupo siguiente constituido por los facetados.

Las diferencias detectadas en las huellas de uso entre tubulares y hendidos, llevaron a Campana a proponer un uso preferencial de los tubulares para la cestería y de los hendidos para el trabajo de la piel (1989: 73). En nuestro conjunto la 


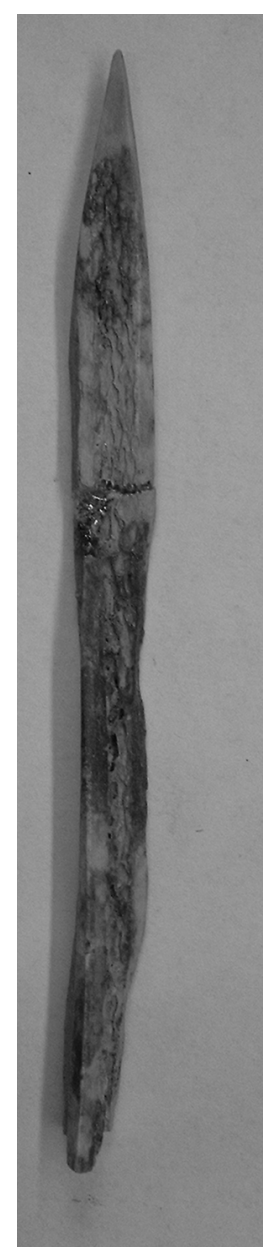

Lam.V. Apuntado hendido (Almizaraque 27).

variabilidad, consideramos que es mayor, siendo las características específicas de cada pieza las que definen su función como alfileres, punzones o gubias.

Un tipo especial incluido en este grupo es el de los hendidos sobre colmillo de jabalí, que como en los casos anteriores, según sus variables técnicas, definirán usos diferentes. En este caso nos encontramos ante colgantes o leznas, según se haya trabajado o no, una punta resistente (con o sin perforación para su suspensión). En la interpretación de estos tipos, los diferentes autores fijan su atención en grupos culturales muy alejados, como es el caso de Polinesia (Pascual, 1998; Sidéra y Legrand, 2006), ya que son estas sociedades las que gracias a economías ganaderas con predominio de suidos, pueden proporcionar algunas pautas de uso para interpretar piezas similares. 


\subsection{Apuntados abrasionados}

Al menos en el exiguo conjunto estudiado, el modo de elaboración no condiciona de forma importante el útil resultante, por lo que los apuntados abrasionados podrían ser englobados en las otras categorías planteadas.

\subsection{Apuntados facetados}

Dentro de los apuntados, el subgrupo de facetados es el que presenta un mayor grado de elaboración, lo que dificulta o imposibilita la determinación del soporte anatómico utilizado.

En el caso estudiado, el elevado número de facetados recomendaba una cuidada subdivisión de tipos, pero los solapamientos hacían muy difícil esta tarea, máxime partiendo de una muestra con un elevado grado de fracturación. Los valores métricos utilizados como pauta, se recogen en la fig. 1.

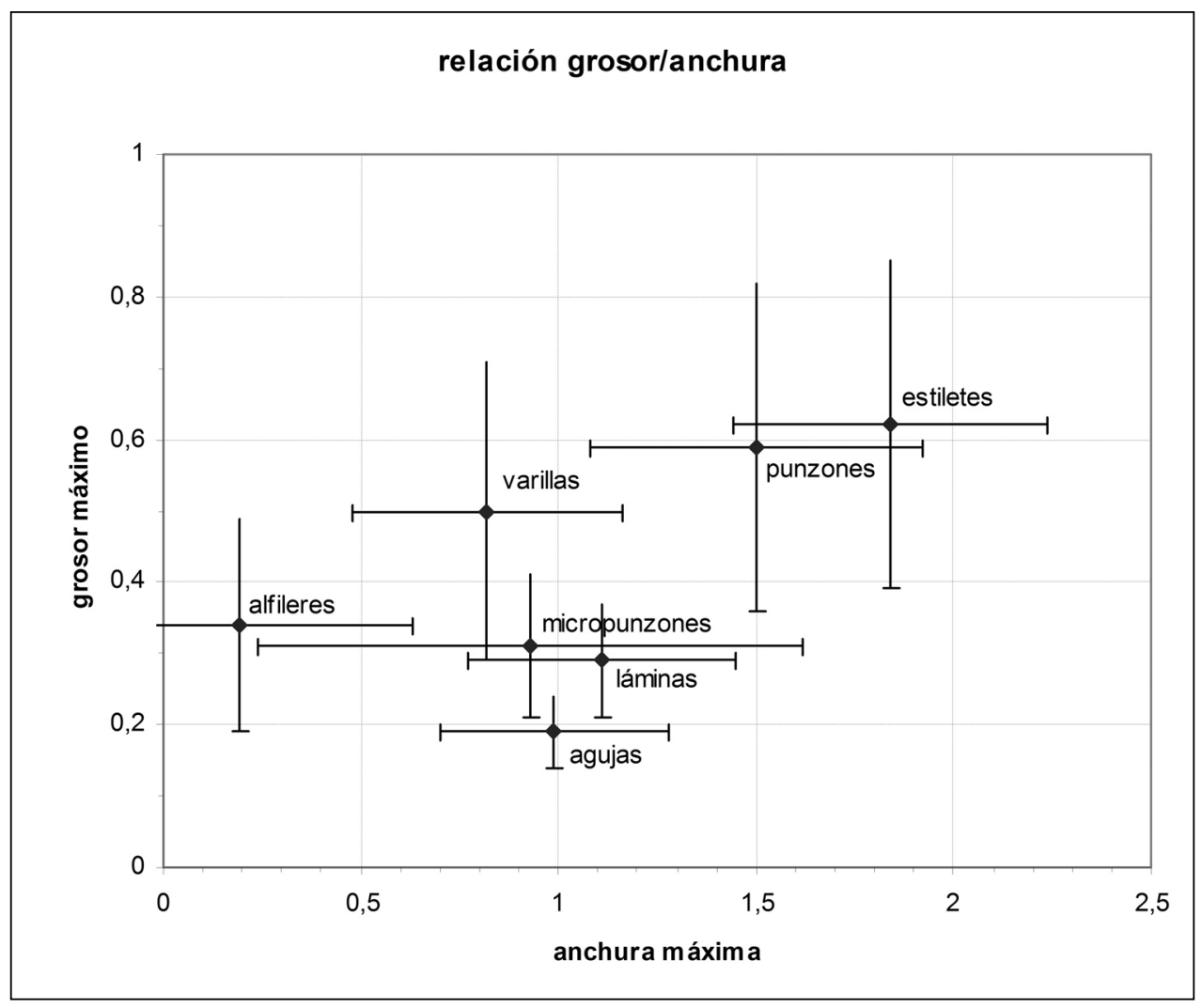

Fig. 1. Gráfico de distribución de medidas por tipos de facetados. Valores medios con desviaciones de $1 \sigma$. 

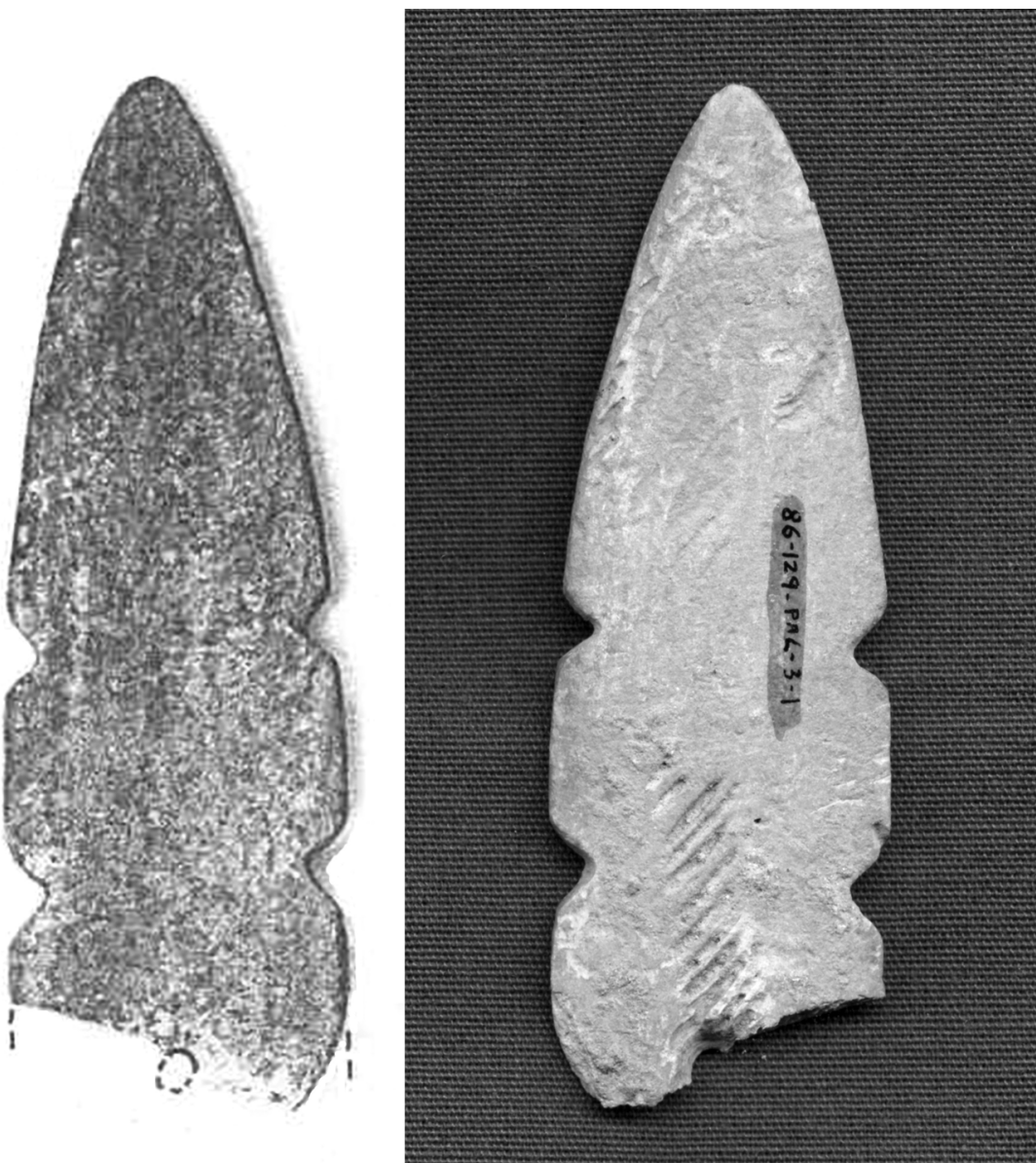

Lam.VI. Puñal de escotaduras de Palaces 4.

Los puñales sensu stricto son escasos, pero entre ellos podríamos diferenciar dos subconjuntos, por un lado los lisos, similares a otras piezas conocidas y los de escotaduras. Estos últimos corresponden al yacimiento de Palacés, en concreto a la sepultura 4. Desgraciadamente están muy fragmentadas, no conservándose ningún ejemplar completo. La pieza que nos ofrece mayor información, presenta un orificio en el área proximal, desgaste en las escotaduras y una punta redondeada. El desgaste de las escotaduras, realizado con algún elemento flexible por fricción, así como la perforación podrían haber sugerido la sujeción de un mango para el puñal. No obstante las características de la punta (muy ancha, redondeada, sin esquirlados, incisiones, ni fracturas) hacen necesario un uso en el que dicha punta no ejerza una acción punzante, pero si pasante, como podría ser el movimiento entre los hilos de un telar. 
Lam.VII. Varilla circular. Almizaraque 40.

Dentro del subgrupo de los apuntados facetados, otro conjunto interesante es el de las varillas. En primer lugar diferenciamos aquellas que no presentan cabeza destacada, clasificadas a partir de sus distintas secciones (laminares, redondeadas e irregulares) y por otro alfileres de cabeza (abanico, de escotaduras y redondeadas) y agujas.

Dado el aumento en el grado de elaboración que presentan estas piezas, así como el tipo de tratamientos que presentan (pulimentos finos, procesos de hervido que fijan la grasa y dan un brillo intenso), su métrica y contextos de aparición, se defiende para ellas un uso ornamental. Algunas conservan restos de ocre similares a las pinturas documentadas en los ejemplares de la Cueva Sagrada de Lorca (Ayala, 1990).

No obstante, existen variantes de uso en este amplio conjunto, así piezas de cabeza redondeada pueden presentar pequeñas facetas de espátula, las varillas de escotadura tienen paralelos en madera que se relacionan en ambientes palafíticos con carretes de hilo (Perini, 1987), y finalmente las agujas tienen una finalidad eminentemente práctica, que comentaremos brevemente.

En el conjunto estudiado tenemos agujas de diferentes características. Ninguna parece ser no obstante, para tejidos finos como serían los de lino, documentados en la Cueva Sagrada de Lorca (Ayala, 1990). Estas agujas para usos más delicados debían tener un menor diámetro y longitud, como las paleolíticas y ante su ausencia en materias perdurables, hemos de pensar que se realizaron en madera. 

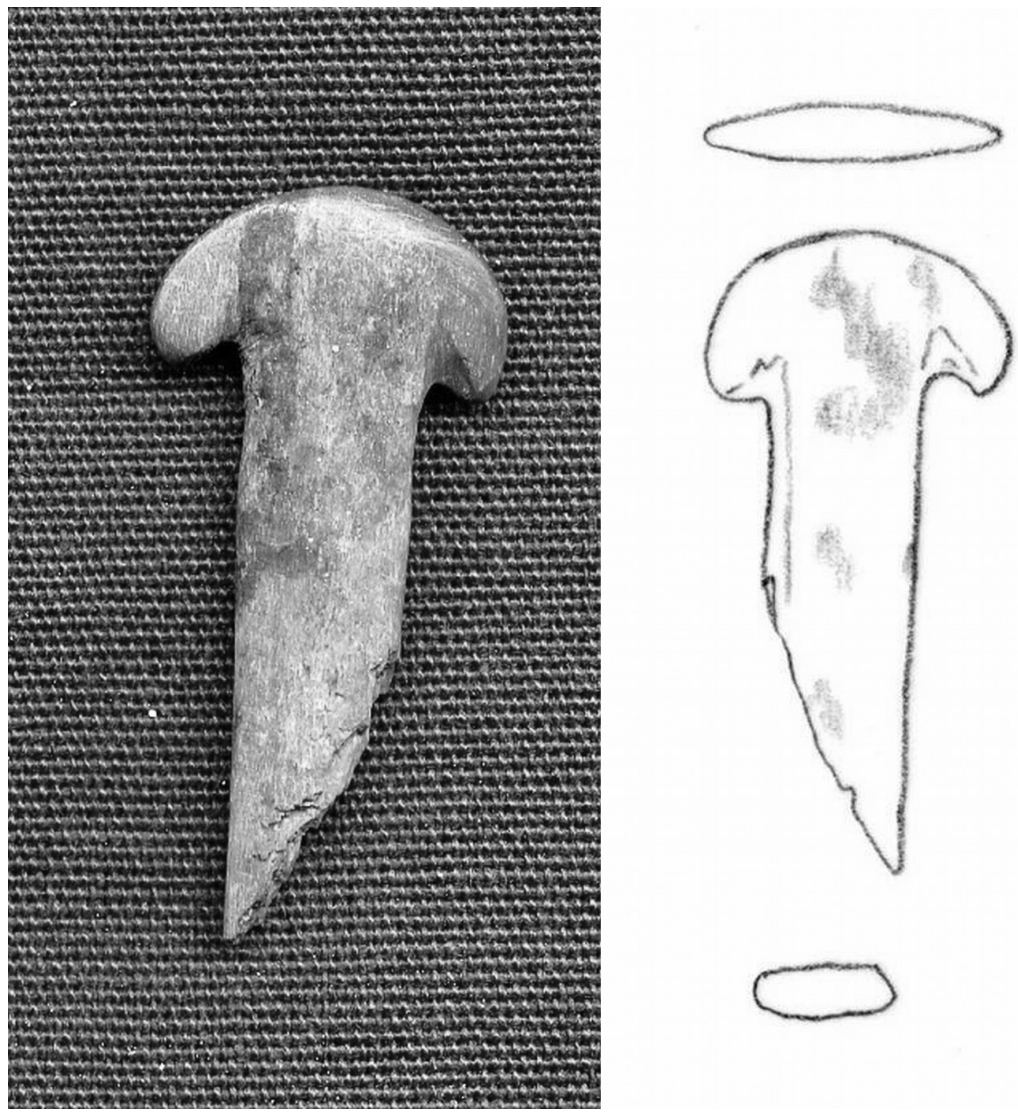

Lam.VIII. Alfiler de La Encantada I.

Un fragmento trabajado en madera procedente del Barranco de los Grajos, conservado entre los fondos del MAN podría aproximarnos a estas piezas.

En algunos casos podemos determinar su conformación a partir de fíbulas de suido y en otros casos de costillas hendidas.

Las agujas cortas observadas ( $5 \mathrm{~cm}$ de longitud), presentan un talón apuntado, con desgastes latero-proximales en un solo borde. El diámetro de la perforación es de 0,3-0,4 cm, lo que indica la utilización de fibras gruesas. Este tipo de agujas, podría servir para el anudado de redes; así como para el cosido de elementos flexibles que proporcionan un intenso brillo, como es el cuero. Las agujas largas de talón recto y cabeza ancha se relacionan con el trenzado de cestería. Finalmente, sólo un ejemplar de Almizaraque, presentaba dos perforaciones, tratándose, pese a su fractura, de una pieza muy larga para su extrema delgadez $(0,1$ grosor). Se trata pues de una pieza que no resistiría fuertes tensiones, pero podría usarse como aguja-pasador de telar. 


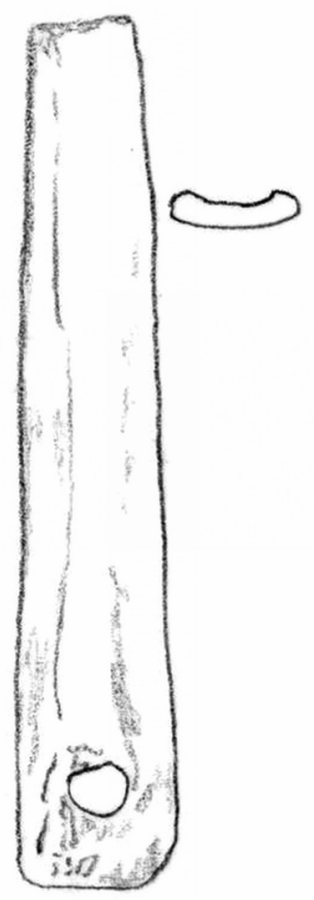

Fig. 2. Aguja del Cabezo del Barranco de Calderón (Albox).

\section{DENTICULADOS}

Entre los denticulados conservados tenemos 4 tipos entre los conjuntos de la Cuenca de Vera:

Las gradinas de dientes pequeños, se documentan en 3 casos, pudiendo estar relacionadas con la decoración cerámica o cuando menos con el arrastre sobre superficies de capacidad plástica similar.

Más numeroso es un segundo grupo de denticulados constituido por útiles que presentan un filo corto dentado, si bien a diferencia de los anteriores, los dientes son largos, sin regularizar y están realizados sobre soportes muy variados. Hemos denominado a estas piezas pseudogradinas. Útiles con huellas poco claras, pero morfométricamente próximos a los rajadores de cestería utilizados para abrir las cañas en partes iguales (Sánchez Sanz, 1982: fig. 7 y 17). 
Los peines, se reducen en este caso a un pequeño fragmento de Jautón 5 , en el que la resistencia de la pieza y sus características técnicas permiten relacionarlo con piezas en mejor estado en las que término y función, son compatibles.

Los 5 denticulados laterales o sierras de la Cuenca de Vera, son piezas muy diferentes entre si. En los casos más delicados pueden asignarse usos ornamentales, mientras que los más toscos podrían utilizarse como sierras para materias blandas. Algunos autores hablan incluso de su utilización como instrumentos sonoros (Coumont, 2003: fig. 1.2), pero en este caso es improbable dados los tamaños y fragilidad de las piezas.

\section{BISELADOS}

La utilización del término espátula ha venido siendo abusiva, ya que el criterio de delgadez es insuficiente para esta atribución, siendo precisa la identificación de un área de trabajo característica.

En el conjunto estudiado, observamos dos grandes grupos de soportes que definen dos subtipos, espátulas sobre costillas y espátulas facetadas sobre soportes no preseleccionados. En el primer caso nos encontramos con piezas usadas en el alisado cerámico, lo que ya demostró Meneses (1994), pero en este conjunto observamos un subtipo significativo, el de las costillas con escotadura central. En el centro de la Península en Tejar del Sastre, se recuperaron piezas similares (Quero, S. 1982: Fig. 19.a) y fuera de España podemos encontrarlas en Francia (Choi y Fages, 1999: fig. 8.4) y en yacimientos palafíticos como Fiavé-Carera ya en la Edad del Bronce de la Italia septentrional (Perini, 1987). A partir de otras piezas sobre costilla con acusados desgastes laterales se atribuye a estos objetos un papel en el desgrane de cereal.

Por su parte las espátulas facetadas, presentan pequeñas áreas trabajadas, relacionables con una tarea delicada o minuciosa. En ellas se puede reconstruir el movimiento seguido por la espátula durante su trabajo probable de aplicación de materias blandas.

Otro biselado frecuente en los conjuntos postpaleolíticos es el cincel, relacionado habitualmente con el trabajo de madera. En nuestro caso los tamaños pequeños indicarían un uso controlado o minucioso.

El empleo de los llamados pulidores no está bien definido, en el caso de la pieza mejor conservada de nuestro estudio, los bordes levemente esquirlados sugieren labores de arrastre con levantamiento, propios de tareas de desescamado o depilado. 


\section{CONTENEDORES}

En este apartado se han incluido mangos sobre asta y sobre diáfisis, así como pocillos realizados sobre soporte malacológico. Entre el primer conjunto tenemos una pieza decorada que podría corresponder a un mango. Fue dibujado por Siret e incluido por él junto a otros elementos de carácter látrico (Siret, 19081995: lam, IX.5), pero dadas las características observadas en la pieza, no consideramos necesario recurrir a categorías no utilitarias.

Los pocillos de concha se diferencian de los elementos de adorno en ocasiones por el tipo de transformación y en otras por la presencia de restos de grasas, resinas, ocre y otros colorantes. El replanteamiento del tema sugiere diversos usos para estos pequeños recipientes según la naturaleza de sus restos, más que por las modificaciones que han sufrido o se han aprovechado (Maicas, 2006).

\section{REDONDEADOS}

Con el concepto utilizado, este grupo queda constituido por un conjunto heterogéneo de piezas cuya característica común es un área de trabajo roma, engloba de este modo piezas que realmente carecen de un área funcional definida, como es el caso de las placas. Este concepto impreciso en el que se recogen objetos que seguramente responden a categorías muy diferentes en su contexto de uso. Así por ejemplo los recortes de cráneo, posiblemente humanos de Jautón 5 . Piezas de estas características se conocen en diversas culturas prehistóricas de Europa. En Arene Candide se documentan dos piezas sobre cráneo humano similares, en un estrato campaniforme que fueron relacionadas con prácticas de trepanación (Bernabo Brea, 1946: 238). No hemos podido constatar trepanación en estos conjuntos, pero para tener un dato seguro a este respecto será necesario desarrollar un estudio específico de los restos óseos conservados. Sea cual sea el resultado en ese sentido, lo que podemos avanzar sobre las piezas estudiadas es que presentan un el perímetro abrasionado tras la extracción, lo que les confiere un significado especial como tal pieza y no como un resto óseo sin transformación.

\section{PERFORADOS}

Este grupo está dominado por los soportes de concha frente a los de hueso y entre estos primeros se destaca la abundancia de Glycymeris sp.

Los brazaletes realizados sobre concha, Glycymeris sp., no se han relacionado con otro uso que no sea el que su nombre define. Además han aparecido en contextos funerarios colocados en el esqueleto en el antebrazo. Su carácter es eminentemente funerario, neolítico y aparte de su aparición en la Costa, destaca su presencia en yacimientos del interior, demostrando la existencia de contactos en- 
tre las distintas zonas. El aprecio que tenían estas piezas se demuestra en su reutilización postfractura mediante la perforación de los extremos para formar brazaletes articulados. En fases posteriores (argáricas), las variaciones en la disposición de las perforaciones y acabados apuntados, permiten pensar en la elaboración de estos elementos como colgantes.

Hay piezas menores que los brazaletes (por debajo de $4 \mathrm{~cm}$ de diámetro), que no obstante no pueden relacionarse con anillos, ni por su tamaño (entre 3,5 y $4 \mathrm{~cm}$ de diámetro), ni por su forma de disco perforado o arandela, imposible de usar en un dedo. Están realizados en nácar extremadamente frágil, posiblemente de origen fluvial, aunque piezas trabajadas sobre Pinctada margaritifera (madre perla) se documentan también en Próximo Oriente (Bar-Yosef, 1997: fig. 6.3).

Los botones simples no se han encontrado en la zona de estudio, pero si contamos con botones de perforación en $\mathrm{V}$ (casquete esférico, cilíndrico, cónico, prismático y de tortuga). Las roturas del puente indican el sentido en el que se ejercía la fuerza, pero pueden corresponder tanto a un desgaste por suspensión de una costura como de un collar. Es difícil precisar el carácter de abotonadura o adorno, pero posiblemente esto no fuese importante para sus antiguos portadores ya que documentos etnográficos actuales, nos muestran como puede cambiarse el sentido de uso de un objeto. En el Norte de la Península se encontró en una sepultura un botón prismático cerrando un collar (Delibes et alii, 1998).

La mayor parte del conjunto malacológico recuperado en los yacimientos de la Cuenca de Vera no es adecuado para el consumo directo. Pero además, la abrasión marina que presentan algunas conchas y las perforaciones debidas a litófagos permiten asegurar que la mayor parte del conjunto, corresponde a individuos que fueron recogidos post-mortem. Si bien este es un aspecto que carece de importancia desde el punto de vista de la funcionalidad del objeto. Los ejemplares recogidos en la playa o aquellos a los que se les practicó una perforación pueden haber servido para idéntico fin. Por otra parte, las piezas ya perforadas en el momento del aprovisionamiento reducen el trabajo que realizar, pero también es cierto que el tiempo necesario para efectuar una de estas perforaciones por abrasión, con los propios cantos marinos que las acompañan es ínfimo (1 a 3 minutos bastan, según el tamaño de la valva).

Entre los gasterópodos perforados más frecuentes, tenemos Conus mediterraneus con desgaste del ápice, producido mayoritariamente por abrasión marina, si bien en algún caso se completan con perforaciones en habitación. Columbella rustica es otra especie abundante, con características similares a la anterior, si bien en este caso, dada su morfología es necesario un mayor tamaño de perforación para introducir el lazo de suspensión desde el ápice o bien realizar la perforación en habitación. Luria luridae, presenta ejemplares uniforados y biforados, siguiendo distintos esquemas de distribución. Otros gasterópodos de menor tamaño y frecuencia en estos conjuntos, presentan esquemas de perforación similares a los de Luria, como es el caso de Marginela sp. y Trivia europea. Hay que tener en cuen- 
ta en este caso, que al tratarse de una colección antigua las especies de menor tamaño pueden verse infrarrepresentadas.

Colgantes y cuentas suponen un grado de elaboración más alto, alejándose de los soportes sobre los que elaboran. Los primeros se definen por un elemento de sujeción o suspensión excéntrico y las segundas por tener la perforación centrada. En el primer tipo podemos encontrar piezas modificadas intencionalmente o recogidas ya con una intensa abrasión natural. Este es el caso de las lúnulas o fragmentos de concha recortados y redondeados por la abrasión marina. Se considera que estas piezas fueron recogidas para servir de materia prima en la elaboración de colgantes, pero en Vera esta lectura se ve entorpecida por su presencia en contextos funerarios.

Otro de los subtipos que podemos destacar es el de los colgantes a imitación de canino atrofiado de ciervo. Copiados desde el Paleolítico en piedra y concha, en la Cuenca de Vera corresponden a contextos neolíticos y se realizaron en concha.

Los colgantes de hueso están facetados haciendo imposible el reconocimiento del soporte, presentan perforaciones bipolares, cilíndricas, en torno a $2 \mathrm{~mm}$ de diámetro y con perfiles lisos propios del uso de punzones metálicos.

El grado de elaboración observado en las cuentas también varía sensiblemente, desde aquellas que podríamos calificar de «aprovechadas" por corresponder a gasterópodos fracturados y abrasionados por el mar, hasta las diminutas cuentas discoidales con un tamaño medio en torno a $1 \mathrm{~cm}$ y perforaciones de 2 $\mathrm{mm}$. Las cuentas discoidales presentan distintos grados de desgaste y en algunos casos parece que nos encontramos ante la posible utilización de cuentas inacabadas. La uniformidad en el diámetro de estas cuentas, plantea un pulimento conjunto.

Para Millares, Siret solicitó la realización de diferentes análisis sobre un importante conjunto de cuentas sobre cáscara de huevo de avestruz y su comparación con otros materiales. Por lo que respecta a la Cuenca de Vera, sólo podemos apuntar la posible presencia de materia prima para su elaboración (Maicas, 2005).

Las cuentas cilíndricas, presentan una escasa trasformación, puesto que la eliminación de las epífisis es suficiente para ensartar el lazo de suspensión, por ello, este es el método más frecuente observado en el caso de las realizadas sobre diáfisis de mamíferos de talla pequeña. Para los soportes preparados sobre diáfisis mayores, se realiza un ranurado de anillos que en muchos casos se terminan de extraer por flexión. En ambos casos se efectúa una regularización de las fracturas/cortes resultantes por abrasión y ocasionalmente pulido. Dentro de este subtipo, destacan las cuentas segmentadas. Su observación indica la existencia de distintos grados de desgaste, así como diferentes métodos de elaboración. Algunas cuentas parecen haber sido muy usadas, mientras que otras fueron utilizadas sin acabar. No es posible saber cuantas fueron parte de un alfiler, pero algunas presentan un desgaste propio de su utilización como cuenta. 


\subsection{Otros perforados}

Entre otros perforados, podríamos citar posibles silbatos o flautas, pero se trata únicamente de dos piezas sobre diáfisis, muy fracturadas y en mal estado de conservación, por lo que no es posible asegurar su carácter.

Dentro del impreciso término «tubos» se pueden recoger un pequeño conjunto de propiedades heterogéneas. Tienen en común el ser piezas cilíndricas con ambos extremos abiertos, iguales pues a las cuentas cilíndricas, pero de mayor tamaño (por encima de los 6,5 cm). El soporte específico utilizado en cada caso supone uno de los aspectos importantes en su caracterización, así como el tamaño y las huellas observadas. La pieza mejor conservada en el conjunto de Vera, está realizada sobre diáfisis de ave de cierta envergadura (posiblemente águila), que presenta marcas de fuego en la mitad del objeto, más intensas en un anillo central. La elección de huesos largos de aves, puede deberse a la delgadez de las paredes de estas diáfisis y a su morfología rectilínea. Estas piezas se vienen relacionando con instrumentos musicales, pulverizadores de pintura, cerbatanas o cañas para líquidos. En el caso de la pieza de Almizaraque 44, las huellas de fuego permiten contemplar un posible uso como boquilla de toberas, algo que ya fue apuntado para las piezas levantinas por Pascual (1998: 94).

\section{ANTROPOMORFOS}

Los rasgos antropoides, generales o parciales, han servido para asignar el término «ídolo» a objetos de difícil interpretación. Otro de los aspectos fundamentales para dicha determinación fue su aparición en contextos funerarios, pero en realidad, muchos pertenecen a hallazgos sin suficiente información o bien se han documentado en contextos de habitación. Asignamos a esta categoría aquellas piezas que carecen de faceta funcional clara.

\subsection{Cruciformes}

Sólo dos piezas fueron asignadas a este tipo, se trata de dos fragmentos de sección plana correspondientes a Jautón 3 y Atalaya 12. En este caso la atribución podría apoyarse en la ergología asociada a las piezas (cruciformes de piedra similares en forma y proporciones). No obstante, un reciente hallazgo en la provincia de Ciudad Real, nos muestra un alfiler cuya cabeza decorada es muy similar al fragmento conservado a la pieza de Atalaya 12 (Barrio y Maquedano, 2000).

\subsection{Falanges}

Las falanges han sido diferenciadas según la intervención que presentan, de mayor a menor complejidad. 


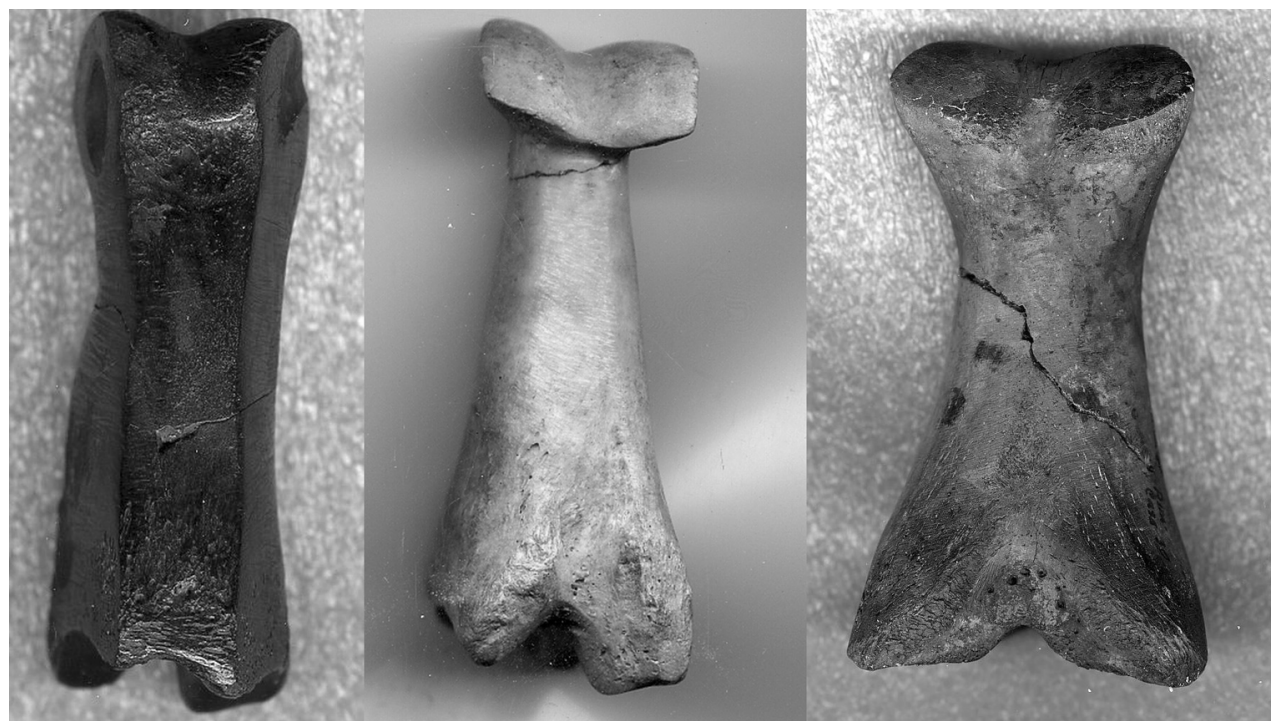

Lam. IX. Falanges de Cervus y Equus trabajadas de Almizaraque.

Las falanges decoradas de la Cuenca de Vera son sólo tres piezas y de ellas, sólo una está grabada al modo de los complejos oculados de Almizaraque, que veremos más adelante.

En otros casos, las falanges presentan modificaciones intencionales desde el suavizado de la forma natural, al total estrangulado de la diáfisis. Otras falanges modificadas presentan perforaciones intencionales, en algún caso, cuadrangulares. Una tercera subdivisión de estas falanges modificadas recogería piezas con fuertes marcas mesiales.

Pensamos que las variaciones substanciales que se observan en el seno de estos subconjuntos determinan funcionalidades diversas. Las marcas mesiales que señalan las diáfisis de algunas de estas falanges corresponden a la fricción intensa de ligamentos, pudiendo corresponder a algún tipo de tensor. Por su parte las falanges perforadas intencionalmente (algunas presentan una perforación indeseada por un exceso de abrasión), se vienen relacionando en contextos paleolíticos con instrumentos aerófonos y finalmente, las que suavizan en mayor o menor medida el perfil natural del hueso son quizá las más próximas al resto de los elementos consignados en este grupo de los antropomorfos. No obstante, en este último conjunto, nos encontramos con una selección de taxones que determinan distintos tamaños, lo que unido a su presencia en sepulturas con restos infantiles y la utilización que de ellas hacen otras culturas, nos permite plantear otras posibilidades para estas piezas a modo de piezas de juego.

Junto a falanges transformadas pueden aparecer otras sin transformación. En lugares de habitación (Almizaraque), las hemos encontrado junto a piezas 
modificadas, pudiendo responder a materia prima almacenada para su transformación. En contextos funerarios, tendríamos que otorgarles un papel similar al de las falanges modificadas mencionadas en primer lugar, ya que aunque se han aducido posibles ofrendas alimenticias, las falanges corresponden a porciones esqueléticas carentes de valor en este sentido.

\subsection{Oculados}

Los oculados de Almizaraque, constituyen un conjunto de 62 piezas, no todas ellas terminadas. Están mayoritariamente realizados sobre huesos largos, con predominio en la elección del soporte de radios que conservan la epífisis proximal y sobre ovicápridos como taxón dominante. No obstante también se realizaron sobre húmeros, costillas y fémur, por lo que respecta a la adscripción anatómica y sobre radios de vaca y caballo en lo referente a otros taxones. Como veíamos en el caso de las falanges nuevamente aquí nos encontramos con una variada selección de soportes que da lugar a objetos de tamaños diferentes.

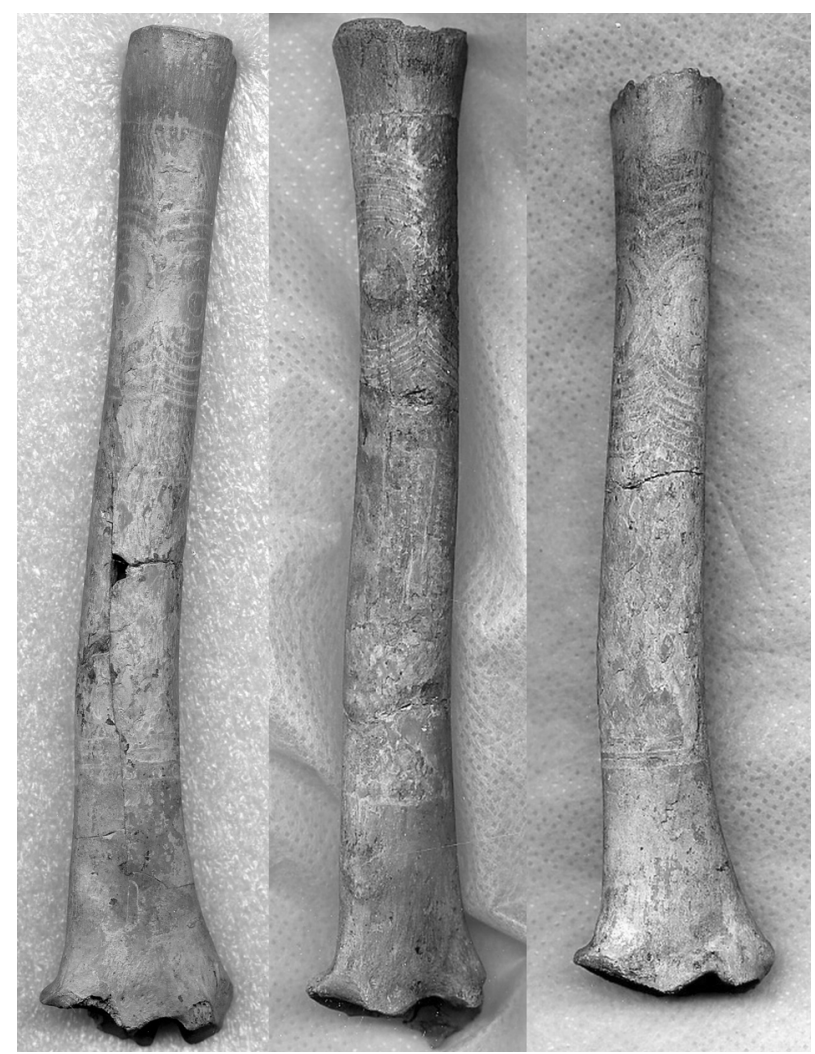

Lam. X. Oculados sobre radio de ovicáprido. Almizaraque. 


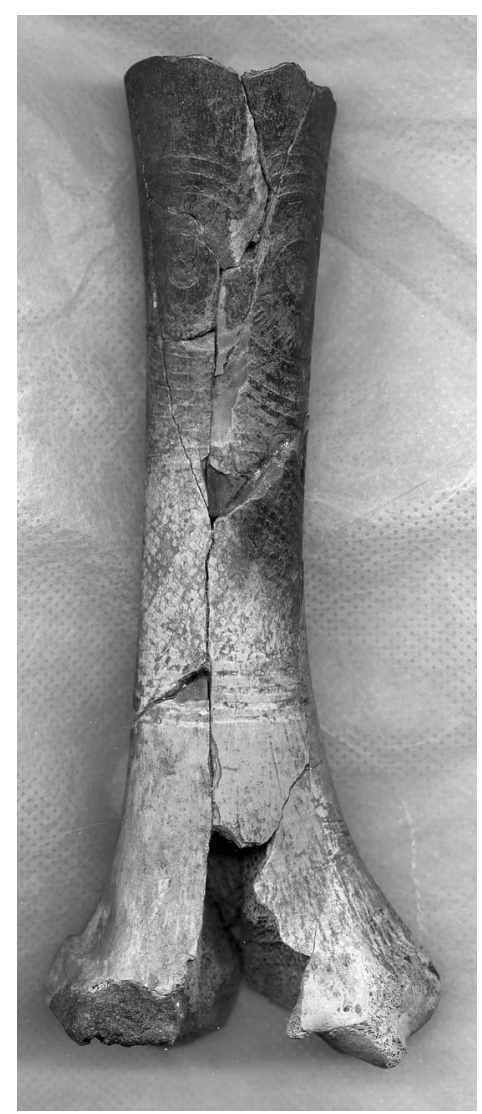

Lam. XI. Oculado sobre radio de Bos de Almizaraque.

Los oculados presentan una decoración que los hace muy similares entre sí, pero pese a la repetición de los motivos iconográficos, el resultado son esquemas compositivos únicos.

La cuidada elaboración de la decoración, contrasta con la escasa atención que recibe el acabado de la pieza que parece realizada para ser observada exclusivamente por su cara anterior. En este sentido, vemos como en algunas piezas no se ha regularizado la cara ventral del hueso, o incluso se ha dejado el arranque de la ulna sin transformación alguna. Además, se trata de piezas huecas, susceptibles de contener en su interior otros elementos.

Otro aspecto significativo de estos «ídolos» es su número y el distinto grado de elaboración que presentan, concentrados en lo que ya Luis Siret llamó «taller de grabador» (Siret, 1908).

Finalmente podemos apuntar un último aspecto notable y es que algunos oculados han sido «borrados». Es decir, una vez concluido el proceso de elabo- 
ración del objeto y tal vez ya amortizado, al menos dos piezas han sufrido una intensa abrasión sobre la zona decorada.

\subsection{Sandaliforme}

Una placa con forma de suela, constituye uno de los elementos más conocidos de la ergología de Almizaraque. Es una pieza plana de hueso, extraída del cráneo de una ballena (F. Poplin, com. personal).

Nuestro sandaliforme presenta decoración por una sola cara, lo que parece indicar que era sólo esta la zona expuesta. El paralelo más próximo para la decoración, lo encontramos en la peineta de la sepultura 12 de Los Millares donde además se recuperó una placa de marfil de forma similar. Tanto en la peineta como en otras piezas del Cerro de las Canteras de Vélez Blanco o de Granada, se conser-

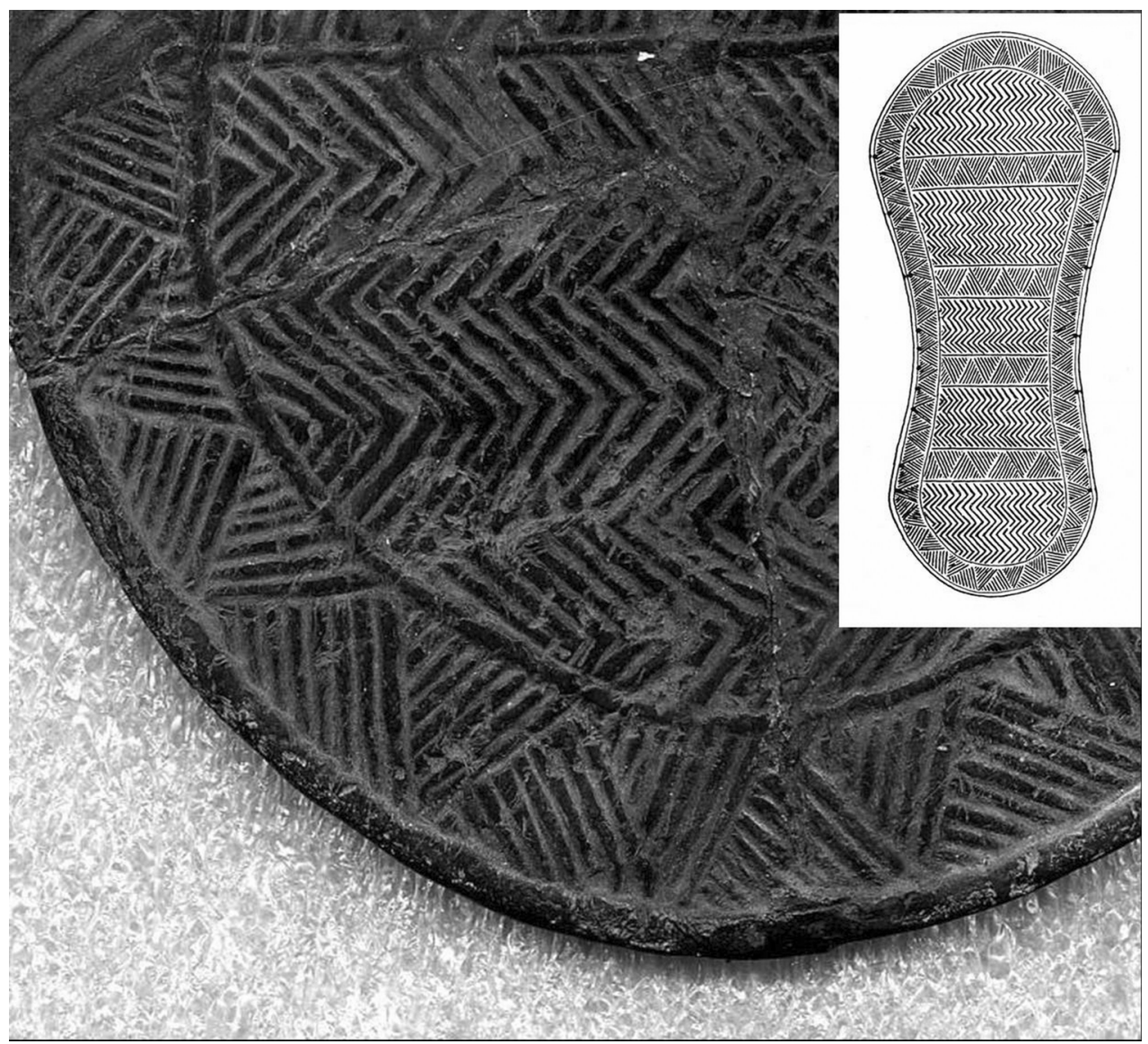

Lam. XII. Detalle de la decoración del Sandaliforme y dibujo de L. Siret (Almizaraque). 


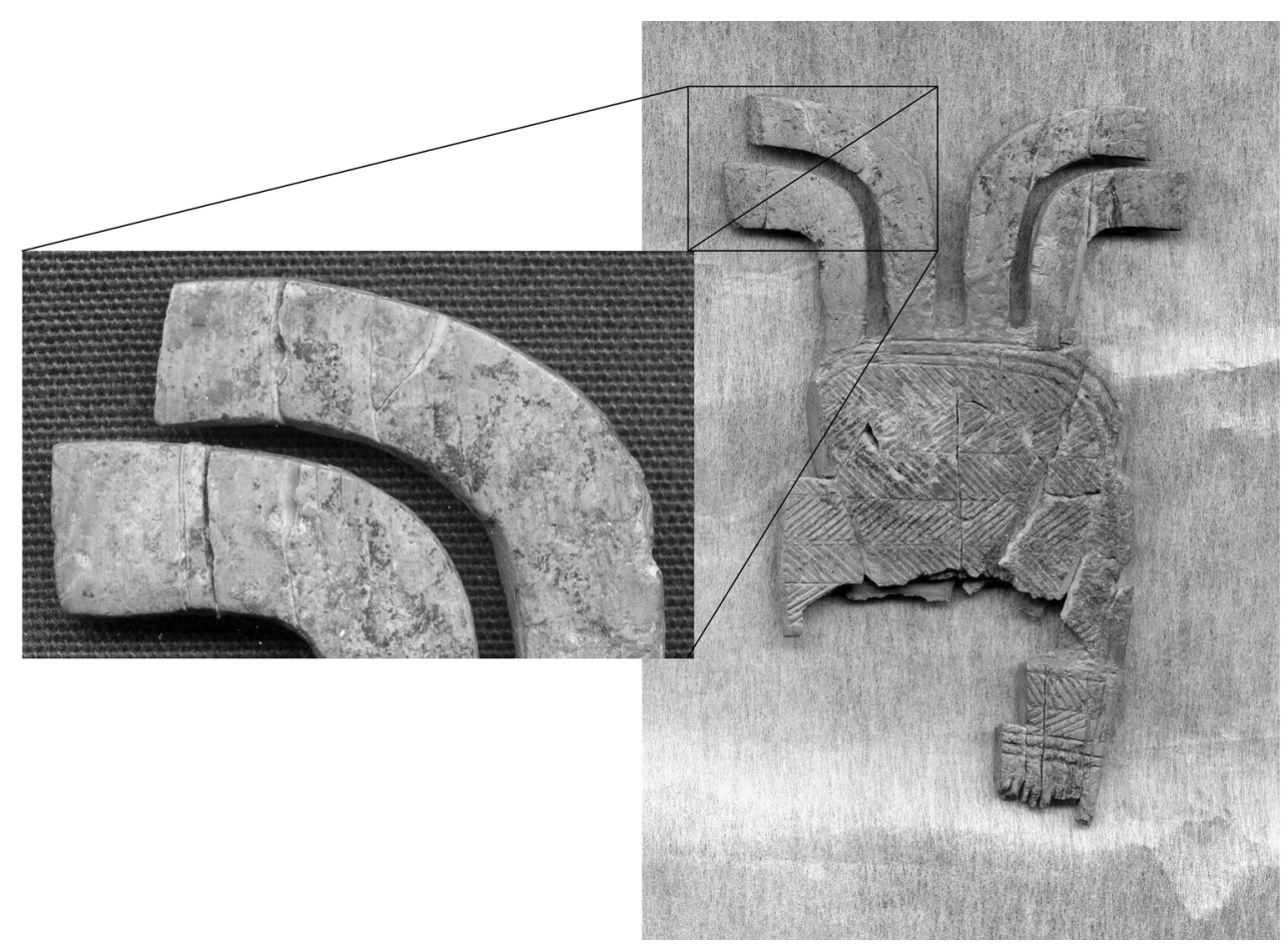

Lam. XIII. Detalle de los restos de pintura de la peineta de Millares 12.

van restos de pintura que posiblemente estuviesen también presentes en las piezas de la Cuenca de Vera.

Las piezas más próximas formalmente al sandaliforme de Almizaraque, son las sandalias de Alapraya (Paço, 1941). Estas placas calizas presentan forma de suela, son dos (derecha e izquierda) y su perímetro está recorrido por una línea de perforaciones como en la pieza de Almizaraque. La resistencia de estos objetos no permitiría su uso como suela, pero dadas sus características si podría tratarse de algún tipo de calzado destinado a un difunto, donde sólo ornamentaría a alguien que no va a descansar su peso sobre el.

\section{CARACTERÍSTICAS GENERALES DEL CONJUNTO}

La industria ósea de Vera presenta un conjunto instrumental de métrica reducida. No aparecen entre los materiales picos de minero, ni grandes cuñas o puñales.

Las preferencias taxonómicas y anatómicas son en líneas generales las esperables en un conjunto postpaleolítico mediterráneo, con particularidades propias como puede ser la presencia abundante de apuntados sobre suido. 


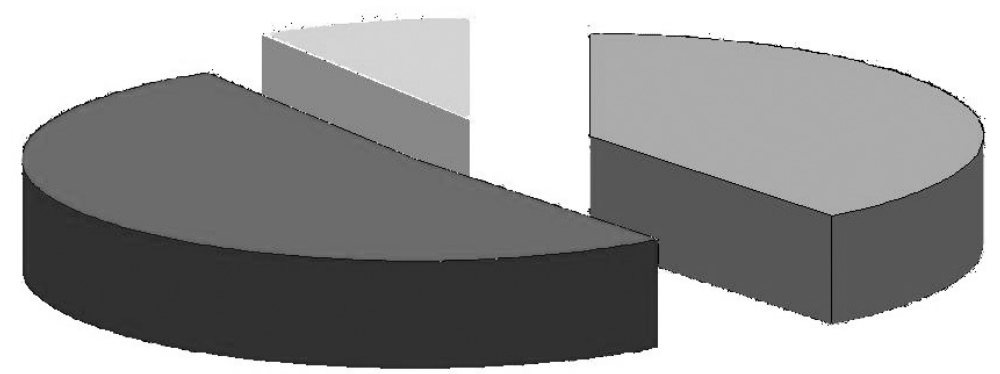

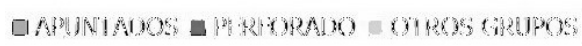

Fig. 3. Distribución de grupos de industria ósea en la Cuenca de Vera.

Predominan los apuntados y perforados, algo que también suele ser frecuente en estas industrias, con porcentajes sensiblemente inferiores para el resto de los grupos.

Las materias dominantes son hueso y concha, con un bajo porcentaje de asta y del resto de materias duras de origen animal (Tabla 1). Dentro de este último apartado se encuentran reflejadas las piezas de marfil. Hemos constatado su presencia en 6 estructuras, pero las dificultades de identificación son importantes, dado que nos encontramos ante piezas de pequeño tamaño y alta transformación, a lo que en ocasiones se suman malas condiciones de conservación. A la espera de datos extraídos de análisis físicos que solucionen la inevitable inexactitud actual, el marfil representa en Vera un $0,63 \%$ del conjunto de su industria ósea, por lo que puede considerarse poco representativo.

Tabla 1. Distribución de objetos de industria ósea por grupos y materias.

\begin{tabular}{|c|c|c|c|c|c|c|}
\hline Grupo & Asta & Concha & Hueso & Marfil & Otros & Total \\
\hline Antropomorfo & & & 140 & & & 140 \\
\hline Apuntado & 21 & 1 & 2.060 & 24 & 25 & 2.131 \\
\hline Biselado & 6 & & 47 & & & 53 \\
\hline Contenedor & 13 & 142 & 7 & & & 162 \\
\hline Denticulado & 2 & & 26 & & 2 & 30 \\
\hline Perforado & & 2.453 & 309 & 4 & 4 & 2.770 \\
\hline Redondeado & 15 & 5 & 12 & & & 32 \\
\hline Múltiple & 4 & 1 & 33 & & & 38 \\
\hline Matriz & 8 & 1 & 6 & & & 15 \\
\hline Indeterminado & 3 & 1 & 6 & 6 & 2 & 18 \\
\hline Total & 72 & 2.604 & 2.646 & 34 & 33 & 5.389 \\
\hline
\end{tabular}


Se constata la existencia de poliútiles, si bien su número debió ser mayor de lo que hoy es posible identificar. Las reutilizaciones también pueden considerarse frecuentes y la presencia en los enterramientos, en líneas generales permite hablar de ajuares funerarios «desgastados» y poco específicos.

La presencia de piezas en proceso de fabricación (metapodios hendidos, oculados inacabados, diáfisis recortadas, valvas en proceso de abrasión, lengüetas de asta, etc.), así como la materia prima almacenada, útiles de fabricación y apuntados reavivados, nos permiten hablar de talleres, que sólo llegarán a tener un cierto grado de especialización en el caso de los oculados de Almizaraque.

Pese a los problemas que una colección antigua plantea a la hora de individualizar contextos, un recorrido por el amplio margen temporal que proponemos a través de la industria ósea permite algunas consideraciones de cambio. Así vemos como la industria ósea aumenta desde el Neolítico al Calcolítico progresivamente, para sufrir un probable descenso en el periodo campaniforme. Los nuevos objetos calcolíticos carecen de tradición clara en las fases anteriores. La complejidad de los tratamientos técnicos realizados sobre los soportes óseos aumenta también durante el Calcolítico, así como la cantidad, calidad y variedad de los conjuntos.

Tabla 2. Porcentaje de industria ósea frente al total de materiales en los yacimientos de la Cuenca de Vera de la Colección Siret.

\begin{tabular}{ll}
\hline Neolítico Antiguo & $11 \%$ \\
\hline Neolítico Reciente & $13,7 \%$ \\
\hline Transición & $23 \%$ \\
\hline Calcolítico + Campaniforme & $23 \%$ \\
\hline
\end{tabular}

Por otra parte, desde el punto de vista geográfico, un espacio vertebrado en torno a los cursos fluviales, tiene en ellos los corredores naturales que favorecen un sentido de circulación entre los productos óseos de la costa, muy valorados en el interior. Estos contactos entre el prelitoral y la Costa se conocían ya entre los cazadores-recolectores del Epipaleolítico; pero ahora también parecen existir comunicaciones a larga distancia, como es el caso de la fachada atlántica, lo que se evidenciaría en la distribución de oculados (con localizaciones intermedias en el interior de La Meseta) o tipos propios de ambas zonas pero extraños en el amplio arco circundante, como es el caso de las puntas de flecha o jabalina.

Con respecto al conjunto del Sureste, se carece por el momento de un análisis global, pero se puede señalar la relevancia de los materiales recuperados en el Cerro de las Canteras y Terrera Ventura, pero especialmente en los conjuntos de GorGorafe y de los Millares. Con respecto al resto de Andalucía, el panorama actual únicamente se apoya en estudios puntuales que ofrecen un panorama heterogéneo, por lo que el mejor referente sigue siendo el área de Levante, donde un es- 
tudio de conjunto permite un análisis global que señala las similitudes en el grupo de oculados, en la distribución porcentual de apuntados, predominio de ovicápridos como soportes, presencia de tipos inusuales como el colgante de perforación sobre elevada, etc., pero que nos indica así mismo diferencias como las observadas por la ausencia en Vera de cucharas y anillos neolíticos o la escasez de apuntados sobre lagomorfo. El caso de Murcia, como es de esperar por su ubicación geográfica intermedia, plantea características propias de ambos conjuntos, acercándose a los levantinos con tipos como los colgantes acanalados, ausentes en Vera, y estará más próximo a nuestros conjuntos en lo referente al trabajo de las falanges; participado en las tres áreas de la relevancia de los facetados destinados a varillas y alfileres.

Se aprecia también una cierta regionalización interna, lógica por las diferencias de biotopo, que se observa a través de la industria ósea en la ausencia de objetos de asta en el interior o de tipos abundantes en la costa como es el punzón sobre fíbula y frente a ello, la presencia exclusiva de ídolos cruciformes o de cuentas segmentadas en el interior.

Los estudios paleoclimáticos detectan aridez ya en las fases previas al Holoceno, aunque durante el Neolítico se considera un denso recubrimiento vegetal (5000 - 3000 a.C.) que durante el III milenio se verá mermado por la intensificación de la acción antrópica que se incrementará en el segundo milenio (Aguayo et alii, 1990; López y López-Sáez, 1994; Pantaleón-Cano, Yll, Roure, 1999; Rodríguez Ariza, 2000). A tenor de estos estudios paleoambientales puede explicarse una posible variación en la disponibilidad de materia prima en la Cuenca de Vera a lo largo de la secuencia propuesta.

Durante las fases asignadas al Neolítico, los yacimientos de Vera presentan una baja representación del trabajo de las materias óseas. A medida que nos adentramos en el Calcolítico, aumenta progresivamente el uso del hueso. Pensamos que una explicación a este hecho puede encontrarse en el retroceso de la madera disponible, material que en estos momentos puede considerarse, el mayor competidor de la materia ósea. No todas las maderas son válidas para la elaboración de útiles, pero existen en este caso, especies muy adecuadas como es el acebuche. En yacimientos como la Draga, o el Barranco de Los Grajos se ha constatado la utilización de la madera de acebuche por su adaptación a las tareas de pulimento. El Calcolítico supondrá no sólo el retroceso de las masas boscosas, sino también de los tres taxones dominantes (Quercus, Olea, Pinaceae).

Además, durante el Calcolítico se produce una mejora de las herramientas de fabricación (metálicas), así como el aumento de la cabaña ganadera disponible.

Pieza a pieza, los objetos analizados nos han permitido considerar nuevas perspectivas para algunos tipos clásicos. Su estudio tecnológico permite defender el surgimiento de artesanías especializadas en los inicios del Calcolítico. Su repartición en el tiempo y el espacio nos ayuda a acercarnos a la evolución y valoración social de estos objetos. 
En conjunto, esta aproximación a la industria ósea del neolítico y calcolítico de la Cuenca de Vera nos permite, contra lo que se pensaba hasta ahora, valorar un corpus rico, tanto cualitativa, como cuantitativamente. Una industria que fue reflejo de procesos de cambio tanto ambientales, como culturales y que presenta una personalidad propia frente a su entorno cultural.

\section{BIBLIOGRAFÍA}

Acosta, P. y CRuz-Auñon, R. (1981): «Los enterramientos de las fases iniciales de la Cultura de Almería», Habis, 12, pp. 275-360.

AyALA, M. ${ }^{\text {a }}$ M. (1990): «Estudio preliminar del ritual funerario calcolítico en la comarca de Lorca, Murcia», Zephyrus, XLIII, pp. 77-86.

BARRIO, C. y MAQUEDANO, B. (2000): «La necrópolis calcolítica de Cerro Ortega (Villanueva de la Fuente)», en Benitez de Lugo, L.: El Patrimonio arqueológico de Ciudad Real. Métodos de trabajo y actuaciones recientes, pp. 67-85.

BAR-YoSEF, D. (1997): “Neolithic shell Bead production in Sinai», Journal of archaeological Science, 24/2, pp. 97-112.

BAR-Yosef, D. (ed.) (2005): «Archaeomalacology. Molluscs in former environments of human behaviour», Proceedings of $9^{\text {th }}$ Conference of International Council of Archaeozoology, Durham. August 2002, Oxbow Books.

Bernabó BreA, L. (1946-1956): Gli scavi nella caverna delle Arene Candide, Instituto Internazionale di Studi Liguri, Génova-Bordighera.

CampanA, D. V. (1989): «Natufian and Protoneolithic Bone Tools. The Manufacture and Use of Bone Implements in the Zagros and the Levant», BAR International Series, 494.

СHOI, S. Y. y FAGES, G. (1999): «L'industrie en matière dure animales du Néolithique final el Chalcolithique de la grotte de Baume Layrou (Trèves, Gard)», Préhistoire d'Os. Recueil d'etudes sur l'industrie osseuse préhistorique. Offert à Henriette Camps-Fabrer, Publications de l'Université de Provence, pp. 227-243

CoumONT, M. P. (2003): «Approche methodologique de l'etude des instruments sonores en os de la Prehistoire: Aspects taphonomiques et fonctionnels», en Patou-Mathis, M., Cattelain, P. y Ramseyer, D. (coord.) : L'industrie osseuse pré-et protohistorique en Europe. Approches technologiques et fonctionnelles, Bulletin du Cercle archéologique Hesbaye-Condroz, XXVI, pp. 87-95.

Delibes, G., ViÑE, A. y Salvador, M. (1998): "Santioste, una factoria salinera en los inicios de la Edad de Bronce en Otero de Sariegos", en Delibes, G. (coord.): Minerales y metales de la Prehistoria Reciente, pp. 155-198.

JoRDA, J. F. (1984-85): «La malacofauna de la Cueva de Nerja (III): Evolución medioambiental y técnicas de marisqueo", Zephyrus, XXXVII-XXXVIII, pp. 143-154

LEISNER, G. y LEISNER, V., (1943): Die Megalithgraber der Iberischen halbinsel: Der Süden, Berlín.

LUJÁN, A. (2004): “Consideraciones sobre el aprovechamiento de restos malacológicos durante la Edad del Bronce en el Levante peninsular», en Hernández Alcaraz, L. y Herández Pérez, M. (ed): En Tierras valencianas y zonas limítrofes, pp. 91-97.

MAICAS, R. (2005): Industria ósea y funcionalidad: Neolítico y Calcolítico en el Sureste de la Península Ibérica, Tesis doctoral, UNED.

- (e.p.): «Objetos de concha: Algo más que adornos en el Neolítico de la Cuenca de Vera (Almería)», Actas del IV Congreso del Neolítico en la Península Ibérica, Alicante, 2006.

Martin de la Cruz, J. C., Delgado Fernández, M. ${ }^{a}$ R., Sanz Ruiz, M. ${ }^{a}$ P. y Vera Rodríguez, J. C (2002): «Novedades en el conocimiento sobre el Neolítico y Calcolítico en Andalucía: panorámica de una década de investigaciones», Muitas Antas. Pouca Gente? Actas do I Coloquio Internacional sobre megalitismo.

Meneses, M. ${ }^{a}$ D. (1994): «Útiles de hueso del Neolítico Final del Sur de la Península Ibérica empleados en Alfarería: Placas curvas, biseles, Placas y Apuntados», Trabajos de Prehistoria, 51, pp. 143-156.

Moreno, R. (1995): «Análisis arqueomalacológicos en la Península lbérica. Contribución metodológica y biocultural», Complutum, 6, pp. 353-382.

PAço, A. de (1941): «Las Sandalias de Alapraya II», Corona de Estudios que la Sociedad española de Antropología, Etnografía y Prehistoria dedica a sus mártires, CSIC, Madrid, I, pp. 213-219. 
Pantaleón-Cano, J., YLL, R. y Roure, J. M. (1999): «Evolución del paisaje vegetal en el Sudeste de la Península Ibérica durante el Holoceno a partir del análisis polínico», Il Congrés del Neolític a la Península Ibèrica, Saguntum-PLAV, Extra-2, pp. 17-23.

Pascual, J. (1998): Utillaje óseo, adornos e ídolos neolíticos valencianos, Servicio de Investigación Prehistórica, Serie de Trabajos Varios, Valencia, 95.

PerinI, R. (1987): Scavi archeologici nella zona palafitticola di Fiavé-Carera. Parte II Campagne 19691976. Resti della cultura materiale metallo, osso, litica, legno, Patrimonio storico e artistico del Trentino, Servizio Beni Culturali della Provincia Autonoma di Trento, 9.

Quero, S. (1982): «El poblado del Bronce Medio de Tejar del Sastre», Estudios de Prehistoria y Arqueología madrileña, 1, pp. 183-247.

Rodríguez ArizA, M. ${ }^{a}$ O. (2000): «El paisaje vegetal de la depresión de Vera durante la prehistoria reciente. Una aproximación desde la Antracología», Trabajos de Prehistoria, 57, pp. 145-156.

Ruiz ParRA, M. (1999): «Los artefactos y arteusos malacológicos de Gatas», Proyecto Gatas. 2. La dinámica arqueológica de la ocupación prehistórica, Arqueología monografías, Junta de Andalucía, Consejería de Cultura, Sevilla.

SÁNCHEZ SANZ, M. ${ }^{a}$ E. (1982): Cestería tradicional española. Editora Nacional, Madrid.

SideRÁ, I. y LEGRAND, A. (2006): «Tracéologie fonctionnelle des matières osseuses: une méthode», BuIletin de la Société Préhistorique Française, 103/2, pp. 291-304.

SIRET, L. (1908-1995): Religiones neolíticas de Iberia, Col. Siret de Arqueología, 2. 